\title{
EL DISCURSO DE J. M. AZNAR ANTES Y DESPUÉS DEL 11 M: LAS MARCAS DE PRIMERA PERSONA EN LA ENTREVISTA POLÍTICA
}

\author{
MARIA Josep MARÍN \\ Universitat Politècnica de València \\ mjmarin@idm.upv.es \\ Àngels CAMPOS \\ Universidad Católica de Valencia \\ angels.campos@ucv.es
}

\begin{abstract}
Resumen
Este artículo analiza la función pragmático-discursiva de las marcas de primera persona en el discurso político. El objetivo del trabajo es comparar el uso de estas marcas en el discurso de J. M. Aznar antes y después de los atentados del 11M. Nuestro corpus está formado por dos entrevistas realizadas a Aznar por la cadena de televisión TeleCinco. La primera tuvo lugar en marzo de 2003 , poco antes de la guerra de Irak; la segunda se llevó a cabo en marzo de 2004, unos días después de los atentados del $11 \mathrm{M}$ y de las Elecciones Generales. El estudio se realiza en dos niveles: por una parte, se clasifican las preguntas efectuadas por el entrevistador según el grado de conflictividad que presentan; por otra, se analizan las marcas de primera persona teniendo en cuenta el referente extratextual; finalmente se interrelacionan ambos aspectos. El trabajo muestra que el uso de las marcas de primera persona en los textos analizados está condícionado por el contexto político en que se desarrollan. Así, a la vez que se pone de manifiesto la relación entre gramática y discurso, se evidencia la conexión entre lenguaje y sociedad.

PALABRAS CLAVE: marcas de primera persona, entrevista política, conflictividad, referente extratextual, contexto político.
\end{abstract}

\begin{abstract}
This paper analyses pragmatic and discoursive functions that first person grammatical marks take in political discourse. The aim of this study is to compare the use of first person marks (verbal terminations, personal pronouns and possessives) in Aznar's discourse before and after 11-M attempts. Our corpus consists of two interviews to Aznar for TeleCinco TV channel. The first one was held on March 2003, before Irak's war; the second one was held on March 2004, some days after $11-\mathrm{M}$ and General Elections. The analysis is twofold: the kind of questions and the kind of first person marks. Firstly, questions that the journalist asks are classified taking to account the conflictivity level. Secondly, first person marks are analysed considering the extratextual reference. The paper demonstrates that there is a relation between grammar and discourse and shows the union between language and society. In fact, the use of these marks is conditioned by politics context.
\end{abstract}

KEY WORDS: first person grammatical marks, political interview, conflictivity, extratextual reference, politics context.

\section{Introducción}

El trabajo que presentamos analiza las marcas gramaticales de primera persona en el lenguaje político. En concreto, hemos realizado un estudio comparativo del funcionamiento de estos elementos en el discurso de José María Aznar en dos entrevistas concedidas a Juan Pedro Valentín, director de los servicios informativos de la cadena de televisión TeleCinco. 
Poco más de un año separan los dos encuentros que, sin embargo, se inscriben en un contexto político bien distinto, marcado, sin duda, por los atentados del 11 de marzo de 2004 en Madrid.

Nuestro estudio se basa en la clasificación de las marcas de primera persona (desinencias verbales, posesivos y pronombres personales) formulada por Campos (2004) y adaptada para los géneros de discurso político en Campos, Marín \& Cuenca (2004). Esta tipología, que parte de las propuestas anteriores de Haverkate (1984), Ciapuscio (1992) y, en especial, Kuo (1999), es un modelo elaborado a partir de los principios metodológicos del análisis del discurso y de la lingüística cognitiva que tiene en cuenta el referente extralingüístico del emisor y la función discursiva de éste. En este trabajo, nos centraremos únicamente en la referencia extralingüística, dado que es el aspecto que aporta datos más relevantes al análisis.

Además, hemos observado la relación de estas marcas deícticas con el tipo de pregunta que realiza el periodista, condicionado a su vez por el marco socio-político en que se lleva a cabo la entrevista. Para ello, hemos reelaborado la propuesta de Stambuk (2003) sobre el conflicto en el cuestionario político y hemos clasificado las preguntas de las dos entrevistas según el grado de conflictividad que presentan. De este modo, la metodología de trabajo ha consistido en identificar en el corpus las diferentes marcas de primera persona e introducirlas en una base de datos, en la cual hemos analizado la marca gramatical concreta en el contexto lingüístico en que aparece, así como el referente extratextual al que hace referencia y el tipo de pregunta a que responde.

La primera entrevista, emitida el 10 de marzo de 2003, se celebra en el Palacio de la Moncloa. El tema central es la posición del gobierno español ante la guerra de Irak. En este sentido, Aznar habrá de justificar por qué se alinea con Estados Unidos y Gran Bretaña en contra de países europeos de tanto peso como Francia, Alemania y Rusia o estados tan poderosos como China. Aunque los inspectores enviados por la ONU no encuentran armas de destrucción masiva en Irak, la supuesta existencia de éstas, que pondría en peligro la seguridad mundial, es el principal argumento para la invasión. La postura de Aznar se opone frontalmente a la práctica totalidad de los partidos mayoritarios de nuestro país e incluso a políticos de su propio grupo. Por otra parte, ciudadanos de todo el mundo salen a la calle durante esos días en multitudinarias manifestaciones antibelicistas.

El segundo encuentro se lleva a cabo en los estudios de TeleCinco, el 22 de marzo de 2004. Aznar, presidente del gobierno en funciones, habrá de abordar dos temas de gran responsabilidad política. En primer lugar, los resultados de la intervención en Irak y, en particular, la influencia que la participación de España en la contienda ha podido tener tanto en los atentados del $11 \mathrm{M}$ como en las Elecciones Generales del 14 de marzo, en las que, contra todo pronóstico, ha resultado vencedor el Partido Socialista. Además, tendrá que justificar la actuación de su gobierno en relación a la información proporcionada a los medios de comunicación y a los ciudadanos sobre la masacre. De hecho, durante la jornada de reflexión, se producen concentraciones ante diversas sedes del Partido Popular para pedir transparencia al ejecutivo, quien, en todo momento manifiesta que la principal línea de investigación es ETA, a pesar de que cada vez es mayor el número de fuentes informativas que relacionan los atentados con el terrorismo islámico.

Ambas entrevistas cuentan con los mismos protagonistas y tienen una duración aproximada (24 minutos y 4.364 palabras, la primera; 31 minutos y 6.020 palabras, la segunda), 
factores que las hacen comparables y contribuyen a dar validez al corpus y a los resultados obtenidos en este estudio. Así pues, a continuación, ilustramos con ejemplos la descripción teórica de los tipos de marca identificados $(\$ 2)$ y de los tipos de pregunta ( $(3)$. El análisis de los resultados obtenidos $(\S 4)$ nos hará ver la relación entre ambos aspectos. Por último, sintetizaremos las conclusiones del trabajo, que revelan cómo el contexto extratextual se manifiesta a través de las marcas gramaticales observadas $(\S 5)$.

\section{Tipos de marca de persona: referente extralinguístico}

Aunque las marcas de primera persona identifican prototípicamente al emisor del mensaje, es evidente que los políticos, en sus discursos, además de representarse a sí mismos, suelen hablar en nombre de un grupo, una nación o una ideología concreta. En efecto, la primera persona del plural es polisémica y en ocasiones ambigua (Zupnik 1994: 341), razón por la cual, en nuestro análisis, hemos distinguido, de un lado, la marca de la primera persona del singular, yo; del otro, diferentes tipos de marca de la primera persona del plural, nosotros, organizados en tres grupos, según el referente extralingüístico determinado por el contexto.

Yo. La primera persona del singular tiene como referente al emisor del mensaje, que asume la total responsabilidad de sus palabras. En las entrevistas analizadas, el referente extralingüístico de la primera del singular puede ser Aznar o Juan Pedro Valentín, aunque en este trabajo nos hemos centrado en las marcas utilizadas por el político entrevistado:

(1) Aznar: Yo no me he presentado a las elecciones, pero mi partido: no ha ganado las elecciones y yo soy de mi partido, el Partido Popular [<sonríe>]; y por lo tanto, todos tenemos responsabilidad en ello ¿no?, como es lógico. Y esas cosas hay que verlas en perspectiva y se requiere cierta perspectiva, cierto tiempo, para analizarlo con tranquilidad, por qué se han producido esos resultados. De todas maneras, yo agradezco muchísimo el que nueve millones seiscientos mil españoles pues hayan confiado en nosotros, del mismo modo que agradezco a los españoles infinitamente el que hayan confiado en mi para durante ser ocho años presidente del gobierno de España, que ha sido para mí un inmenso honor. (E2, 11-19)

Nosotros. La primera persona del plural puede tener diversos referentes según las personas que incluye (emisor, receptor, tercera persona) y las relaciones que se dan entre ellas. Así, hemos agrupado las marcas del nosotros en tres grandes bloques, exclusivo, inclusivo y generalizador, teniendo en cuenta el alcance más o menos amplio del referente extratextual.

a) Nosotros exclusivo. El plural más cercano a la primera persona del singular es el nosotros exclusivo, ya que se trata de un nosotros que no incluye al receptor inmediato, con el que se comparte la situación comunicativa. Hemos encontrado dos tipos: Nos 0 y Nos $l^{1}$.

1 En el debate electoral, el nosotros exclusivo más utilizado es el que designamos Nos7. Tiene como referente al emisor y puede incluir al receptor indirecto (receptor 2), es decir, a los telespectadores, pero excluye total o parcialmente al receptor directo (receptor 1), presente en la situación comunicativa. Se trata de un tipo de marca que apenas aparece en la entrevista, pero muy habitual en el debate, puesto que a través de ella se resaltan las diferencias entre el político, que habla como representante de su partido, y el resto de participantes, que personifican a sus respectivos grupos (Campos, Marín \& Cuenca 2004: 289). El único caso de Nos7 en nuestro corpus aparece en boca del periodista (i): 
Nos 0 : emisor $+3^{a}$ persona. Se trata de un plural referencial que incluye al emisor y a una tercera persona no presente en el intercambio, en este caso, no presente en la entrevista. En nuestro corpus, el referente extralingüístico de este tipo de plural es muy diverso, sobre todo en la primera entrevista (E1), donde puede hacer referencia al grupo formado por los dirigentes de Estados Unidos, Gran Bretaña y España (2a), a las Naciones Unidas (2b) o al gobierno español. Sin embargo, en la segunda entrevista (E2), este tipo de nosotros suele hacer referencia prácticamente en todos los casos a los políticos del gobierno español ( $2 \mathrm{c})$ :

(2) a.Entrevistador: Luego, zes suficiente, según su opinión, eh:, la resolución 1441 para que se produzca esta intervención militar? A_ además [(de que haya una segunda resolución)]

Aznar: [(Desde el punto de vista)] de la legalidad internacional, eso es así. Desde el punto de vista de lo que puede significar una:_ un_ un deseo, una conveniencia, una: esperanza de tener nuevas posibilidades a que una intervención finalmente no se produzca, pues una nueva resolución sería muy positiva, ¿no? Por eso luchamos por ella y trabajamos por ella. $(\mathrm{E} 1,147)$

(2) b.Entrevistador: [...] Eh., si: no hay una resolución de Naciones Unidas aprobando una intervención militar en Irak, ¿España podría, eh:, apoyar esa: intervención?

Aznar: [...]Ahora no tenemos que plantearnos ese escenario en el día de hoy, tenemos que plantearnos el escenario de decir, hagamos el mayor esfuerzo por conseguir el mayor consenso posible. ¿Con qué objetivo? Con el objetivo que se desarme, Sadam Hussein. Ese es el objetivo de las Naciones Unidas [...] (El, 101)

(2) c. Aznar: No, perdón, nosotros abrimos una línea de investigación inmediatamente en ese terreno, pero le habla una persona que nunca ha distinguido entre terrorismos. En España tenemos casi 200 muertos encima de la mesa. (E2, 153)

Nos 1: emisor. Este tipo de nosotros se corresponde con el tradicionalmente denominado plural de modestia o pseudo-inclusivo (Haverkate, 1984: 86), ya que equivale a la primera persona del singular. Por lo tanto, en nuestras entrevistas, el referente extralingüístico de esta marca puede ser, de nuevo, Aznar o el entrevistador. En (3) Aznar utiliza la primera del plural de esta manera:

(3) Entrevistador: ¿Cree que la mayoría de los españoless entienden (<pronunciación enfática $>$ ) y respaldan la postura que está: manteniendo el gobierno español?

Aznar: [...] Porque ese régimen es una amenaza para todos. Para España también, para los ciudadanos españoles también. En sus vinculaciones con el terrorismo, en la utilización de armas de intervención masiva. Piense usted que no estamos hablando de grandes divisiones acorazadas, de grandes armamentos, no. Estamos hablando de que un poco de ántrax puede causar una catástrofe. $(E 1,299)$

(i) Entrevistador: Ahora mismo, en debate Naciones Unidas se está centrando, por un lado, en los inspectores, y por otro lado en segundas resoluciones, en la que, la verdad es que hemos tenido que hacer un curso rápido para: enterarnos de: cuáles son los procesos, ¿no? [...] (E1,40) 
b) Nosotros inclusivo. El siguiente grupo identificado es el nosotros inclusivo, ya que incluye tanto al emisor como al receptor. Según que la relación entre ellos sea asimétrica o equilibrada hablaremos de Nos 3 o Nos $4^{2}$.

Nos3: emisor + receptor. Hace referencia al emisor y al receptor, pero predomina el receptor, que es, en realidad, quien debe realizar la acción. Esta marca es muy habitual como atenuante de actos directivos ${ }^{3}$. En el ejemplo que sigue, Aznar, situándose en un segundo plano y focalizando sobre los receptores, se sirve del Nos 3 para intentar que tanto su interlocutor como los telespectadores lleven a cabo la acción que los conduciría a compartir su visión del mundo:

(4) Aznar: [...] Pero una persona como yo que ha dicho siempre y he sido criticado por eso que todos los terrorismos son iguales. $Y$ una persona que, como yo, que he dicho que la principal amenaza que tiene el mundo en este momento es el terrorismo y que había un tiempo de terrorismo después del once de Septiembre, que había declarado la guerra al mundo occidental, que había declarado la guerra a Occidente. Y eso o queremos verlo o no queremos verlo. $(\mathrm{E} 2,209)$

Nos4: emisor + receptor. Este plural es el más prototípico de los inclusivos, ya que se refiere al emisor y al receptor en igualdad de condiciones, por lo tanto se corresponde con el inclusivo tradicional (Haverkate 2004: 89). En nuestro corpus, hace referencia a los dos participantes en la entrevista:

(5) Aznar: [...] Lo peor que podía ocurrir en esta crisis, en esta situación, es que las Naciones Unidas salieran derrotadas, es que: dictadores, como Sadam Hussein, es que terroristas pues se diesen cuenta que se puede desafiar a la las Naciones Unidas y el desafio se gana. $Y$ yo le pregunto a: a gente que nos puede estar viendo, a tantas y tantas personas nos pueden estar viendo, que imaginen un mundo en estas circunstancias, que imaginen un mundo en cual las Naciones Unidas sin credibilidad, que imaginen un mundo en que la legalidad no es respetada. $[\ldots](\mathrm{E} 1,32)$

c) Nosotros generalizador. Por último, los plurales de más amplio alcance son los generalizadores, que agrupan al emisor, al receptor y a una tercera persona genérica. Dentro de este grupo, hemos distinguido dos clases, según que la tercera persona colectiva tenga menor o mayor alcance, el Nos 5 y el Nos6.

Nos5: emisor + receptor $+3^{\text {a }}$ persona colectiva. Incluye al emisor, al receptor y a una tercera persona, no presente en el intercambio comunicativo, que suele hacer referencia a

2 En otros corpus, hemos encontrado también el nosotros inclusivo que designamos Nos2, un tipo de plural bastante utilizado en los textos científicos, pero sin representación en las entrevistas analizadas. Paralelo al Nos3, se refiere como éste al emisor y al receptor, pero con un papel predominante del primero: el emisor realiza una acción e invita al receptor a seguirlo, aunque el verdadero protagonista de la operación es él. El siguiente caso, extraído de Campos (2004: 263), nos proporciona un ejemplo:

(ii) Consideremos ahora una molécula como un sistema de cargas puntuales que interaccionan sólo electrostáticamente (coulombianamente) entre sí. 
una comunidad determinada. En nuestro corpus, este plural se refiere mayoritariamente a los españoles (6):

(6) Aznar: Los españoles votan lo que quieren. $Y$ en esta ocasión, han votado lo que quieren. Lo hicieron en el año dos mil [<sonríe>], lo hicieron en mil novecientos noventa y seis, lo hicieron antes y lo harán después. [...] España tiene un nivel de bienestar material como no hemos tenido nunca. Deseamos que en nuestro país se siga creando empleo, deseamos que la convivencia constitucional siga garantizada. $Y$ deseamos que nuestro país siga prosperando internacionalmente y nacionalmente y para eso trabajaremos. $(\mathrm{E} 2,144)$

Nos6: emisor + receptor $+3^{\mathrm{a}}$ persona universal. Es el plural más amplio y, por consiguiente, se acerca mucho a las marcas de impersonalidad. Incluye a todo el mundo en sentido genérico y, con frecuencia, aparece acompañado de todos o todo el mundo (7):

(7) Aznar: [...] Pero por eso yo le preguntaba antes y preguntaba en voz alta cuáles son las alternativas a la seguridad en el mundo. Porque se pueden plantear muchas al_ escenarios y muchas alternativas. Antes hemos hablado de Kósovo, antes hemos hablado de Milósevic. Hoy estamos todos más tranquilos porque Milósevic no está. $(\mathrm{E} 1,192)$

En nuestro corpus, según muestra el ejemplo anterior, el nosotros universal deja al margen, como es lógico dado el contexto, a dictadores y terroristas, y se refiere a la gran mayoría de los habitantes de la aldea mundial, que desean la paz y defienden la democracia.

\section{La conflictividad positiva en la entrevista política: tipos de pregunta}

Dado el indiscutible protagonismo de los medios de comunicación en nuestra sociedad, los políticos saben que cualquier intervención pública que realizan se dirige fundamentalmente a los ciudadanos, puesto que está determinada por lo que André-Larochebouvy (1984) denomina «triangulación». Se trata de una cualidad propia (aunque no exclusiva) del acontecimiento massmediático que, como interacción comunicativa, "a los papeles participativos de emisor y receptor, suma el de un segundo receptor: el oyente/espectador, que generalmente es pasivo, múltiple y anónimo." (Gallardo 1998: 82). En efecto, esta presencia implícita de un receptor indirecto, que es, en realidad, el verdadero destinatario del mensaje, constituye un rasgo fundamental que enmarca las características generales del lenguaje político: la ambigüedad (que permite al emisor, cuando lo desea, hablar sin comprometerse), el carácter polémico (relacionado con la creación discursiva de un adversario) y la intención movilizadora (ya que, como texto argumentativo, el discurso político está encaminado a provocar una determinada reacción en el ciudadano) (Fernández Lagunilla 1999, Marín 2005a).

Desde este punto de vista, podríamos afirmar que en el debate electoral destaca la intención movilizadora, puesto que tiene como objetivo fundamental conseguir el voto del ciudadano, mientras que en la entrevista política adquiere más relevancia el carácter polémico del discurso político, ya que es un acontecimiento comunicativo que suele realizarse en momentos socio-políticos conflictivos, donde se dan posiciones enfrentadas que a menudo 
constituyen el tema central del encuentro. Precisamente, en esta idea se basa el concepto de "conflictividad positiva" sugerido por Stambuk (2003) para el cuestionario político:

[...] No es conflictivo el cuestionario, no es conflictivo el periodismo o el periodista, es parte de la relación dialógica adecuada para el producto entrevista política, donde el tema predominante es el conflicto, la polémica, el disenso, la confrontación. El apellido positiva, valida la actitud del periodista como un ejercicio permitido, justificado, de modelo adversarial [...]. (Stambuk 2003)

En efecto, para esta autora, que considera el conflicto un componente esencial de la política, la toma de decisiones políticas supone generalmente una situación problemática en la que se ven implicadas opiniones y posturas diferentes, a menudo polémicas. Las declaraciones de los políticos se convierten así en un medio a través del cual expresar su posición respecto a sus rivales ${ }^{4}$. Es entonces cuando entra en juego la labor del entrevistador, quien, si quiere realizar un buen trabajo, deberá hacerse eco de la situación y asumir la voz de la opinión pública y de las posiciones contrarias al entrevistado.

Esta perspectiva permite a Stambuk distinguir diferentes tipos de preguntas, teniendo en cuenta las intenciones del periodista y el grado de conflicto que conllevan ${ }^{5}$. La reinterpretación de su clasificación nos ha servido de base para formular una propuesta que nos permite identificar, entre las preguntas de las dos entrevistas que hemos analizado, tres tipos de cuestiones según el grado de conflictividad positiva que indican: preguntas que piden definición, preguntas que manifiestan confrontación y preguntas que muestran insistencia.

a) Preguntas que piden definición. Las preguntas que piden definición sobre ideas o acciones son las que presentan menor grado de conflictividad, ya que su objetivo, la búsqueda de información básica o la solicitud del punto de vista del invitado, constituye la función principal del entrevistador en este género. La demanda de definición puede hacer referencia a ideas y acciones propias $(8 \mathrm{a})$ o ajenas $(8 \mathrm{~b})$ :

(8) a. Entrevistador: ¿No se arrepiente en nada de? Se lo preguntaban recientemente en una rueda de prensa y usted dijo que no era el momento, espero que éste si lo sea ¿no se arrepiente en nada de las decisiones que ha tomado, por ejemplo, en politica exterior con motivo, por ejemplo, de la guerra de Irak? (E2, 345)

(8) b. Entrevistador: [(¿Cree que)] Francia y Alemania hacen el juego a Sudam Hussein con su postura? $(\mathrm{E} 1,203)$

4 En este sentido, la conflictividad positiva que caracteriza la entrevista política para Stambuk podría considerarse equivalente, como rasgo diferenciador, a lo que en otros trabajos hemos denominado (des)cortesía política dentro del debate electoral (Marin 2005b).

5 Para su clasificación, Stambuk se basa en un grupo de 52 entrevistas (escritas) realizadas a políticos con cargos de responsabilidad en cualquier ámbito (legislativo, gubernamental o municipal) en los suplementos semanales de los principales rotativos chilenos y las revistas de información general más significativas del país. Como resultados más destacados, señala que el $73^{\prime} 12 \%$ de las preguntas realizadas manifiestan conflictividad positiva, mientras que el $23 \%$ son de tipo informativo. 
Como se observa en (8b), este tipo de preguntas incluye a menudo verbos del tipo creer, pensar, opinar... Además, entre ellas, podemos encontrar algunas cuestiones en las que el entrevistador sintetiza la respuesta del entrevistado para que éste asienta y su postura quede más clara $(8 \mathrm{c})$ :

(8) c. Aznar: [...] España en todo caso va a estar en el_ en_ bajo el amparo de las Naciones Unidas, porque: en el supuesto de que no se obtuviese un consenso para una nueva resolución, todas las resoluciones de las Naciones Unidas están vigentes, todas. $Y$ todas obligan al desarme. $Y$ todas advierten a Sadam Hussein, la 1441, que se expone a grandes consecuencias. Por lo tanto estamos, en cualquier caso y en cualquier supuesto, ante lo que indica el mandato de las Naciones Unidas y sus resoluciones. Otra cosa distinta es que nosotros queremos reforzar ese mandato y hacer mayor esfuerzo de consenso. Vamos a intentarlo, a ver si es posible.

Entrevistador: Luego, ¿es suficiente, según su opinión, eh:, la resolución 1441 para que se produzca esta intervención militar? $A_{-}$además [(de que haya una segunda resolución)]

Aznar: [(Desde el punto de vista)] de la legalidad internacional, eso es así. (E1, 140)

b) Preguntas que manifiestan confrontación. Consideramos preguntas de confrontación aquellas en las que el entrevistador contrasta las afirmaciones y acciones del entrevistado con afirmaciones o acciones de fuentes discrepantes ( $9 a)$ y también, aunque en menor medida, con afirmaciones o acciones de fuentes afines al protagonista de la entrevista ( $9 \mathrm{~b}$ ) e incluso con afirmaciones o acciones que el propio político ha realizado en situaciones anteriores $(9 \mathrm{c})$ :

(9) a. Entrevistador: Francia, Rusia y China ya han dicho claramente que no van a permitir una: segunda resolución, ¿eh: qué escenario no:s eh: coloca: esa postura de esos tres paises? (El, 148)

(9) b. Entrevistador: $Y$ estos datos y estos documentos que ustedes han desclasificado eh lo que están haciendo es apuntar al CNI como el culpable de haber dicho, en un principio, que era ETA; es decir, el gobierno dice: "el CNI me dijo que era ETA". [( ¿No es esto un desprestigio para el CNI?)] $(\mathrm{E} 2,82)$

(9) c. Entrevistador: En la Junta General del su partido, usted dijo que había cometido errores, que usted personalmente habia cometido errores. Eh ¡cuáles son esos errores? (E2, 21)

Podemos ver que, entendida en sentido estricto, no es la pregunta la que manifiesta confrontación, sino que la confrontación suele aparecer como preámbulo. Por esta razón, en ocasiones, la intervención del entrevistador en este tipo de cuestiones puede resultar bastante extensa, como en (9b), donde el periodista sitúa a Aznar cara a cara con acciones de su gobierno.

c) Preguntas que muestran insistencia. En las preguntas que muestran insistencia, el entrevistador pide abiertamente al entrevistado que concrete una intervención ambigua o persiste en la búsqueda de respuesta ante una cuestión que ha sido eludida. Son, por tanto, 
las preguntas que implican un grado mayor de conflictividad, dado que el entrevistado se resiste a contestar de manera explícita. Formalmente, suelen aparecer precedidas de marcadores discursivos del tipo pero, entonces... (10):

(10) Aznar: [...] Lo que a mí me importa ahora es que la posición de España sea una posición fuerte, que sea una posición sólida, que no se manden mensajes equivocados, que no es haciendo concesiones al terror, como el terror (se va a ganar). En ese sentido, yo estoy absolutamente seguro que el próximo Gobierno de España, si actúa en esa línea, tendrá todo el apoyo del Partido Popular.

Entrevistador: ¿Retirar las tropas de Irak es una concesión al terror?

Aznar: Pues me parece un gravísimo error

Entrevistador: Pero ¿Es una concesión al terror?

Aznar: Es_Sin duda, se ha tomado muy buena nota de lo que eso quiere decir. Entrevistador: ¿Se ha tomado muy buena nota por parte de quién?

Aznar: Por parte, evidentemente, de quien se puede beneficiar del terror o de los propios terroristas $[\ldots] .(\mathrm{E} 2,259)$

El ejemplo (10) contiene una serie continuada de preguntas en las que el entrevistador se enfrenta de manera sistemática a la ambigüedad del entrevistado y nos permite observar ambos tipos de cuestiones de insistencia. Así, la primera y la tercera intervención del periodista pretenden que el entrevistado puntualice sus insinuaciones; en cambio, la pregunta central insiste ante una respuesta evasiva.

\section{Análisis de los resultados obtenidos}

En este apartado recogemos los resultados obtenidos del estudio de las 419 marcas de primera persona utilizadas en total por José María Aznar en los dos encuentros. En primer lugar, presentamos y comentamos los datos referentes a las marcas, a continuación, los vinculados a las preguntas $y$, finalmente, los obtenidos al relacionar los diferentes tipos de marca con la clase de pregunta a que responden.

\subsection{Resultados relativos a las marcas}

Comenzaremos destacando que la proporción de marcas utilizadas en ambas entrevistas es muy similar: el 3' $\%$ del total de palabras en la primera entrevista (E1) y el $4^{\prime} 2 \%$ en la segunda (E2). Sin embargo, en cuanto a la aparición concreta de los diferentes tipos de marca en cada encuentro, sí que se dan diferencias importantes, como indica la tabla 1: 
Tabla 1. Distribución de marcas por entrevista

\begin{tabular}{|c|c|c|c|}
\hline Tipos de MARCA & Entrevista 1 & Entrevista 2 & TOTAL \\
\hline YO & $77\left(45^{\prime} 8 \%\right)$ & $159(63,5 \%)$ & $236(56,3 \%)$ \\
\hline$\overline{N o s} \theta$ & $59\left(35^{\prime} 1 \%\right)$ & $61(24,2 \%)$ & $120\left(28^{\prime} 6 \%\right)$ \\
\hline Nosl & $7\left(4^{\prime} 1 \%\right)$ & $1\left(0^{\circ} 4 \%\right)$ & $8\left(1^{\prime} 9 \%\right)$ \\
\hline Nos. exclusivos & $66\left(39^{\prime} 3 \%\right)$ & $62\left(24^{\prime} 6 \%\right)$ & $128(30,5 \%)$ \\
\hline$\overline{N o s 3}$ & - & $2\left(0^{\prime} 8 \%\right)$ & $2\left(0^{\prime} 5 \%\right)$ \\
\hline Nos4 & $2(1 ’ 2 \%)$ & - & $2\left(0^{\prime} 5 \%\right)$ \\
\hline Nos. inclusivos & $2\left(1^{\prime} 2 \%\right)$ & $2(0,8 \%)$ & $4(1 \%)$ \\
\hline $\operatorname{Nos} 5$ & $11\left(6^{\prime} 5 \%\right)$ & $26\left(10^{\prime} 3 \%\right)$ & $37\left(8^{\prime} 8 \%\right)$ \\
\hline Nos6 & $12\left(7^{\prime} 2 \%\right)$ & $2\left(0^{\prime} 8 \%\right)$ & $14(34 \%)$ \\
\hline Nos. generalizadores & $23\left(13{ }^{\prime} 7 \%\right)$ & $28(11 \% 1 \%)$ & $51(12,2 \%)$ \\
\hline NOSOTROS & $91(54,2 \%)$ & $92\left(36^{\prime} 5 \%\right)$ & $183(43,7 \%)$ \\
\hline$\overline{\text { TOTAL }}$ & $168(100 \%)$ & $251(100 \%)$ & $419(100 \%)$ \\
\hline
\end{tabular}

Estos datos nos permiten hacer las siguientes observaciones:

a) Las marcas mayoritarias en el corpus analizado son el yo y el Nos0, nosotros exclusivo que incluye al emisor y a una $3^{\mathrm{a}}$ persona no presente en el intercambio. También resultan destacables las marcas de Nos 5 y Nos6, el nosotros generalizador, que incluye al emisor, al receptor y a una $3^{\mathrm{a}}$ persona genérica. En cambio, apenas es perceptible la presencia del nosotros inclusivo.

b) En E1, las marcas de la primera del plural (54'2\%) superan ligeramente a las de la primera del singular $\left(45^{\prime} 8 \%\right)$. La más relevante es el NosO $\left(35^{\prime} 1 \%\right)$, que corresponde a tres referentes extralingüísticos distintos: el grupo formado por los dirigentes políticos de EEUU, Gran Bretaña y España; la ONU; el gobierno español. Le siguen en importancia las marcas generalizadoras, el Nos 5 y el Nos6, que, con una distribución igualada (6'5\% y $7 \cdot 2 \%$ ), tienen como referentes respectivos a los españoles y a todo el mundo democrático.

c) En E2, el yo $\left(63^{\prime} 5 \%\right)$ domina de manera evidente sobre el nosotros $\left(35^{\prime} 5 \%\right)$. Entre las primeras personas del plural, sobresale también el $\operatorname{Nos} 0\left(24^{\prime} 2 \%\right)$, aunque sin llegar a la representatividad que tenia en E1. Esta marca exclusiva únicamente tiene ahora un referente extralingǘstico: el gobierno español. En cuanto a las marcas generalizadoras, el Nos5, referido a los españoles, realiza asimismo un papel destacable $\left(10^{\prime} 3 \%\right)$, mientras que el Nos6, todo el mundo, apenas tiene presencia $\left(0^{\prime} 8 \%\right)$.

\subsection{Resultados relativos a las preguntas}

Respecto al tipo de preguntas realizadas en cada una de las entrevistas, la tabla 2 muestra los datos numéricos obtenidos: 
Tabla 2. Distribución de preguntas por entrevista

\begin{tabular}{|l|c|c|c|c|}
\hline Preguntas & Definición & Confrontación & Insistencia & TOTAL \\
\hline E1 & $14\left(58^{\prime} 3 \%\right)$ & $9(37,5 \%)$ & $1(4,2 \%)$ & $24(100 \%)$ \\
\hline E2 & $17(34,6 \%)$ & $15(30,6 \%)$ & $17(34,8 \%)$ & $49(100 \%)$ \\
\hline
\end{tabular}

Los datos expuestos apuntan hacia los siguientes hechos:

a) En E1, el entrevistador se centra en la definición de la postura política del entrevistado ( $58^{\prime} 3 \%$ de las preguntas), con la intención de conocer a fondo las razones que llevan a Aznar a actuar de una manera tan decidida en contra de la opinión europea mayoritaria. También es importante para el periodista la confrontación de la posición que el invitado defiende con las de otros países y líderes mundiales que mantienen actitudes opuestas (37'5\%). Apenas necesita insistir con sus preguntas $\left(4^{\prime} 2 \%\right)$, porque el líder político contesta con seguridad y $\sin$ reservas.

b) En E2, el entrevistador mantiene una actitud similar en cuanto a confrontación (30’6\% de las cuestiones) y compara nuevamente la actuación del entrevistado con otras reales o posibles. Sin embargo, el interés por solicitar el punto de vista de Aznar ha dado paso, en muchos casos, a la insistencia por conseguir de él respuestas concretas (de hecho, las preguntas de insistencia se han situado en el 34\% $8 \%$, dando alcance a las de definición, el $34^{\prime} 6 \%$ ), ya que el político se muestra esquivo y ambiguo en sus contestaciones.

c) La segunda entrevista contiene muchas más preguntas que la primera, 49 frente a 24. Este resultado no puede justificarse por el hecho de que dure 6 minutos más, sino que más bien ha de relacionarse con turnos más breves de Aznar, así como con el incremento de las preguntas de insistencia, que son, en general, escuetas.

\subsection{Relación entre tipo de marca y tipo de pregunta}

En este apartado, exponemos los resultados correspondientes a la relación entre los distintos tipos de marca utilizados por el entrevistado y los diferentes tipos de pregunta realizados por el entrevistador. La tabla 3 presenta los datos correspondientes a El y la tabla 4 los obtenidos en E2: 
Tabla 3. Entrevista 1: tipo de marca en relación al tipo de pregunta ${ }^{6}$

\begin{tabular}{|c|c|c|c|c|c|}
\hline \multirow{2}{*}{ Tipos de MARCA (E1) } & \multicolumn{4}{|c|}{ Tipos de pregunta } & \multirow{2}{*}{ TOTAL } \\
\hline & $\mathbf{N}$ & Definición & Confrontación & Insistencia & \\
\hline YO & - & $27(16 ' 1 \%)$ & $49\left(29^{\prime} 2\right)$ & $1(0,6 \%)$ & $77\left(45^{\prime} 8 \%\right)$ \\
\hline Nosotros exclusivo & - & $25\left(14^{\prime} 9 \%\right)$ & $40\left(23^{\prime} 8 \%\right)$ & $1\left(0^{\prime} 6 \%\right)$ & $66\left(39^{\prime} 3 \%\right)$ \\
\hline Nosotros inclusivo & - & $2(1 ' 2 \%)$ & - & - & $2(1 ' 2 \%)$ \\
\hline Nosotros generalizador & $1\left(0^{\prime} 6 \%\right)$ & $5(3 \%)$ & $17\left(10^{\prime} 1 \%\right)$ & - & $23\left(13^{\prime} 1 \%\right)$ \\
\hline NOSOTROS & $1(0 ' 6 \%)$ & $32(19 \%)$ & $57(33,9 \%)$ & $1\left(0^{\prime} 6 \%\right)$ & $91(54 ' 2 \%)$ \\
\hline TOTAL & $1\left(0^{\prime} 6 \%\right)$ & $59\left(35^{\prime} 1 \%\right)$ & $106(631 \%)$ & $2(1 ' 2 \%)$ & $168(100 \%)$ \\
\hline
\end{tabular}

A la vista de estos resultados, podemos afirmar respecto a la primera entrevista:

En E1, las respuestas a preguntas de confrontación son las que contienen más marcas de primera persona (63’1\%); mediante ellas, el entrevistado argumenta a favor de sus propias opiniones y acciones y en contra de las ajenas. Para estas argumentaciones, Aznar se sirve principalmente de marcas de primera persona del plural (33'9\%), en particular de las exclusivas $\left(23^{\prime} 8 \%\right)$ y de las generalizadoras $\left(10^{\prime} 1 \%\right)$. En este sentido, muestra, a través de las marcas utilizadas, que cuenta con el respaldo político de su gobierno, la ONU y, especialmente, la coalición formada por EEUU y Gran Bretaña (Nos)), y que el objetivo de su posición es salvaguardar la seguridad mundial (Nos6) para afianzar la seguridad de los españoles (Nos5). Asimismo, tienen un papel muy destacado para responder a preguntas de confrontación las marcas de primera persona del singular, mediante las cuales Aznar se representa discursivamente a sí mismo como persona y como político seguro de sí mismo, dado el peso específico de su apoyo en el nivel internacional y la mayoria absoluta con la que gobierna en España.

En esta entrevista, también ocupan un lugar relevante las marcas que responden a preguntas de definición $\left(35^{\prime} 1 \%\right)$, donde el nosotros en conjunto $\left(19^{\prime} 1 \%\right)$ vuelve a superar al yo $(16 \%)$, aunque por poca diferencia. Así pues, el político se vale fundamentalmente del yo y del nosotros exclusivo (14'9\%), lo que equivale a decir que, para definir su punto de vista, se apoya nuevamente en él mismo, en su gobierno y en el patrocinio internacional.

Apenas encontramos una marca relacionada con preguntas de insistencia. 
Tabla 4. Entrevista 2: tipo de marca en relación al tipo de pregunta

\begin{tabular}{|l|c|c|c|c|c|}
\hline \multirow{2}{*}{ Tipos de MARCA (E2) } & \multicolumn{4}{|c|}{ Tipos de pregunta } & \multirow{2}{*}{ TOTAL } \\
\cline { 2 - 6 } & $\mathbf{N}$ & Definición & Confrontación & Insistencia & \\
\hline YO & $\mathbf{2 ( 0 , 8 \% )}$ & $\mathbf{5 3}(\mathbf{2 1 , 2 \% )}$ & $\mathbf{6 4}(\mathbf{2 5 , 6 \% )}$ & $\mathbf{4 0}(\mathbf{1 5 , 9 \% )}$ & $\mathbf{1 5 9}(\mathbf{6 3 , 5 \% )}$ \\
\hline Nosotros exclusivo & - & $13(5,1 \%)$ & $26(10,3 \%)$ & $23(9,2 \%)$ & $62(24,6 \%)$ \\
\hline Nosotros inclusivo & - & $2(0,8 \%)$ & - & - & $2(0,8 \%)$ \\
\hline Nosotros generalizador & - & $9(3,5 \%)$ & $18(7,2 \%)$ & $1(0,4 \%)$ & $28(11,1 \%)$ \\
\hline NOSOTROS & - & $\mathbf{2 4}(\mathbf{9 , 4} \%)$ & $\mathbf{4 4}(\mathbf{1 7 , 5} \%)$ & $\mathbf{2 4}(\mathbf{9 , 6} \%)$ & $\mathbf{9 2}(\mathbf{3 6 , 5 \% )}$ \\
\hline TOTAL & $\mathbf{2 ( 0 , 8 \% )}$ & $\mathbf{7 7 ( 3 0 , 6 \% )}$ & $\mathbf{1 0 8}(\mathbf{4 3 , 1} \%)$ & $\mathbf{6 4}(\mathbf{2 5 , 5} \%)$ & $\mathbf{2 5 1}(\mathbf{1 0 0} \%)$ \\
\hline
\end{tabular}

Respecto a la segunda entrevista, los datos de la tabla 4 indican:

En E2, han descendido mucho las marcas relacionadas con las preguntas de confrontación (hasta el 43'1\%) y han aumentado de manera inversamente proporcional las relacionadas con las preguntas de insistencia $\left(25^{\prime} 5 \%\right)$, mientras que las usadas para contestar preguntas de definición se mantienen (30'6\%). En las respuestas a las tres clases de cuestiones, se da un uso mayoritario del yo, mediante el cual el político asume su responsabilidad en la situación?.

En cuanto a la primera persona del plural, entre las marcas vinculadas a preguntas de confrontación hay una acusada caída del nosotros exclusivo (que se queda en el 10'3\%), hecho que resulta lógico puesto que en las circunstancias políticas en que se encuentra el país (Aznar debe enfrentarse a hechos tan duros como los atentados de Madrid y, en otro orden de cosas, la pérdida estrepitosa del poder) poco o ningún valor tiene la ayuda exterior y el solo apoyo con el que puede contar Aznar es el de su gobierno, único referente extralingǘstico al que ha quedado reducido el Nos0. Cercanas a las exclusivas, las marcas generalizadoras ( $7^{\prime} 2 \%$ ), sólo aparecen de manera destacable en las preguntas de confrontación y con ellas el político quiere dejar claro que ha hecho lo que consideraba mejor para los españoles.

En las preguntas de definición, el nosotros no tiene demasiada relevancia $\left(9^{\prime} 4 \%\right)$, pues en ellas, a través del yo (21'2\%), Aznar asume de manera evidente la responsabilidad de su postura y defiende con tenacidad el punto de vista que ha guiado su actuación, sin acudir demasiado a otros referentes extralingüísticos. Sin embargo, para hacer frente a la contundente aparición de preguntas de insistencia, junto a la marca de primera del singular (15\% $9 \%$, utiliza también el nosotros exclusivo referido su gobierno $\left(9^{\prime} 2 \%\right)$, dando a entender que el gabinete ha respaldado sus acciones.

7 Sin embargo, en esta segunda entrevista, el número de marcas reforzadas del yo, aquellas en las que aparece el pronombre personal sujeto acompañando al verbo, ha disminuido respecto de la primera (del $50 \%$ al $35 \%$ ). Parece, pues, que en E2 Aznar asume, pero manifiesta menos seguridad en sí mismo. 


\section{Conclusiones}

El estudio de las marcas de primera persona en dos entrevistas políticas realizadas por Telecinco a J. M. Aznar ha puesto de manifiesto la relevancia de estos elementos como indicadores discursivos del contexto extralingüístico y de la imagen que el político quiere ofrecer de sí mismo, de su partido y de sus aliados políticos. De hecho, el análisis de estas marcas deícticas, a partir de la identificación de varios referentes extratextuales, nos ha llevado a observar que su utilización por parte del entrevistado se relaciona con el grado de conflictividad de las preguntas que el periodista entrevistador realiza, las cuales, a su vez, se hacen eco de la situación socio-política del momento.

Las marcas más utilizadas en el corpus analizado son el yo, el nosotros exclusivo y el nosotros generalizador. Mediante la primera persona del singular, el entrevistado se representa a sí mismo como persona y como político: J. M. Aznar, presidente o presidente en funciones del gobierno español. Destaca su uso en la segunda entrevista, donde asume responsabilidades y defiende su actuación.

En cuanto al nosotros, con la marca exclusiva $(\operatorname{Nos} 0)$, Aznar se representa a sí mismo junto a una tercera persona no presente en el intercambio pero muy eficaz a la hora de apoyar sus actuaciones: en la primera entrevista, para argumentar a favor de la invasión de Irak, tiene referentes tan poderosos en la escena política como la ONU o los presidentes de EEUU y Gran Bretaña; en la segunda, hace referencia únicamente al gobierno de Aznar. Por otra parte, el nosotros generalizador permite al político justificar sus posiciones en favor del bien común, ya se ciña a los ciudadanos de su propio país (Nos5) o abarque a la mayoría de los habitantes del globo (Nos6). Resulta comprensible que no aparezcan apenas marcas de nosotros inclusivo, ya que la entrevista política suele darse en situaciones socio-políticas conflictivas en las que el entrevistador ha de poner sobre la mesa opiniones contrarias a las del entrevistado.

En este sentido, en las entrevistas analizadas, la pérdida de poder político del entrevistado coincide con el aumento de la conflictividad positiva en las preguntas del periodista. Así, el primer encuentro, que tiene lugar cuando Aznar gobierna en mayoría absoluta y cuenta con el apoyo de los Estados Unidos en política exterior, nos muestra a un presidente del gobierno español que recibe cordial a las cámaras de TeleCinco en el Palacio de la Moncloa y responde, seguro, a las preguntas de J. P. Valentín. En cambio, en el segundo, Aznar acaba de perder las elecciones y gran parte del país cuestiona su actuación durante los atentados del $11 \mathrm{M}$. En esta ocasión, encontramos en los estudios de TeleCinco a un presidente en funciones con semblante grave y renuente a contestar con claridad algunas de las cuestiones planteadas por el periodista, que, con la merma de peso político de Aznar, presentan mayor grado de conflictividad.

En síntesis, podemos afirmar que las marcas de primera persona son una estrategia discursiva a tener muy en cuenta en el análisis del discurso político y, en particular, en el género de la entrevista. De hecho, su utilización constituye un mecanismo de argumentación implícita muy efectivo para el político cuando se trata de aludir al contexto extralingüístico y mostrar una imagen determinada ante el público. 


\section{Referencias bibliográficas}

André-Larochebouvy, Danielle (1984): La conversation quotidienne. París, Crédif.

Campos, Àngels (2004): La inscripció de la persona en el discurs acadèmic: un estudi contrastiu català-castellà-anglés. Valencia, Universitat de València, Tesis Doctoral, http://www.tdx.cesca. es/TDX-0519105-131352/.

Campos, Àngels, Maria Josep Marín y Maria Josep Cuenca (2004): "Las marcas de primera persona en el debate electoral" en Soares da Silva et al. (eds.) 2004: 279-298.

Ciapuscio, Guiomar E. (1992): "Impersonalidad y desagentivación en la divulgación científica", Linguïstica Española Actual, 14/2, págs. 183-205.

Cuenca, Maria Josep (1995): "Mecanismos lingǘsticos y discursivos de la argumentación", Comunicación, Lenguaje y Educación, 25, págs. 23-40.

Gallardo Paúls, Beatriz (1998): Comentario de textos conversacionales II. Los textos. Madrid, Arco/ Libros.

Fauconnier, Gilles (1985): Mental Spaces: Aspects of Meaning Construction in Natural Language. Cambridge (Mass.), The MIT Press.

Fernández Lagunilla, Marina (1999): La lengua en la comunicación política. Madrid, Arco/Libros, 2 vols.

Haverkate, Henk (1984): Speech Acts, Speakers and Hearers. Amsterdam, John Benjamins.

Kuo, Chih-Hua (1999): "The use of personal pronouns: role relationships in scientific journal articles", English for Specific Purposes, 18(2), págs. 121-138.

Marín Jordà, Maria Josep (2003): Discurs i gramaticalització. Verbs de percepció usats com a marcadors discursius en el debat electoral. Valencia, Universitat de València, Tesis Doctoral, http://www.tdx.cesca.es/TDX-0721104-094020/.

Marín Jordà, Maria Josep (2005a): Marcadors discursius procedents de verbs de percepció. Argumentació implicita en el debat electoral. València, Universitat de València, Anejo $n^{0} 59$ de Quaderns de Filologia.

Marín Jordà, Maria Josep (2005b): "El debat electoral: la (des)cortesia necessària?", Actas del First International Conference on CDA, Cd-Rom. València, Universitat de València.

Soares da Silva, Augusto et al. (eds.) (2004): Linguagem, cultura e cogniçaõ. Coimbra, Almedina.

Stambuk, Patricia (2003): "La entrevista en la comunicación política: una mediación desvirtuada", Sala de Prensa 60, vol. 2. http://www.saladeprensa.org/art491.htm (11-2-05).

Tang, Ramona y Sughanti John (1999): "The 'I' in identity: Exploring writer identity in student academic writing through the first person pronoun", English for Specific Purposes, 18, págs. S23-S39.

Zupnik, Yael-Janette (1994): "A pragmatic analysis of the use of person deixis in political discourse", Journal of Pragmatics, 21, págs. 339-383. 